\title{
A Redação de Textos Técnico-Científicos
}

\author{
Marco-Aurélio De Paoli * \\ mdepaoli@iqm.unicamp.br \\ Universidade Estadual de Campinas, Instituto de Química
}

\section{Informações do Artigo Resumo}

Histórico do Artigo A redação de um texto didático, dissertação, tese e projetos ou relatórios

Criado em Fevereiros de 2003 científicos, abrange várias etapas comuns, desde um levantamento

Atualizado em Julho de 2004 bibliográfico adequado e a leitura atenta dos principais trabalhos a serem citados, até a escrita do primeiro rascunho, que servirá de base para as modificações que resultarão na versão final. A formatação das páginas, a organização de tabelas e figuras e a escrita do resumo, entre outros tópicos, necessitam de atenção e dedicação, para que a qualidade desejada seja

Palavras-Chaves

Redação

Texto técnico-científico

Formatação de texto

Projetos

Relatórios

Dissertações

Teses

Publicações

Patentes obtida. Este texto pretende indicar os passos a serem seguidos por aqueles que necessitam produzir textos técnicos-científicos [1].

\section{Projetos}

Um projeto é apresentado para solicitar uma Bolsa de Estudos, um Auxílio à Pesquisa ou como um adendo a um Convênio de Pesquisa. De qualquer forma, é sempre o primeiro passo para o desenvolvimento de um projeto de pesquisas. Por esta razão a sua redação é discutida em primeiro lugar.

As etapas da redação de um projeto são:

1. Definição de um tema em termos da duração pretendida, do tempo disponível e do nível do trabalho (estágio técnico, iniciação científica, aperfeiçoamento, mestrado, doutorado, pós-doutorado, projeto de pesquisa, etc).

2. Levantamento bibliográfico e leitura dos principais trabalhos.

3. Redação da $1^{\text {a }}$ versão contendo:

Título: curto e suficientemente atraente para chamar a atenção sobre o trabalho; não deve parecer com um resumo do projeto.

Agradecimentos

Aos meus orientados e colegas que fizeram sugestões e correções deste texto. Aos meus orientados que me obrigaram a repetir todas estas instruções ao longo destes 27 anos de trabalho como orientador. Agradeço particularmente à Profa. Carol H. Collins que corrigiu este texto e quase todas as minhas publicações em inglês. 
Introdução: o "estado da arte" no assunto, o mais abrangente possível. Deve também situar o trabalho no contexto da instituição e do grupo de pesquisas onde o projeto será desenvolvido.

Objetivos do projeto: texto curto indicando as metas a serem alcançadas ou as hipóteses levantadas e que serão comprovadas ou contestadas.

\section{Metodologia a ser usada:}

i. Materiais.

ii. Equipamentos. Informar: se estão disponíveis no laboratório ou na instituição, se estão funcionando de forma regular e se já foi treinado para usá-los (se não foi, incluir o treinamento no cronograma). Se for usar equipamentos de outra(s) instituição(ões), incluir uma carta o autorizando a usá-los.

iii. Procedimentos experimentais a serem usados (sínteses, purificação, caracterizações, análises, etc). Para ensaios normatizados basta citar o número da norma, e.g., ASTM - D 2378.

iv. Métodos de medida e de cálculo. Indicar os programas de computador que usará (tem licença? está disponível na rede da instituição? é grátis ?).

Cronograma de execução do projeto: prever relatórios, reuniões, treinamentos, exames de qualificação, exames de idiomas, etc.

\section{Bibliografia atualizada.}

\section{Correção da $1^{\text {a }}$. versão. \\ 5. Redação da versão final. \\ 6. Submissão do projeto.}

Em seguida são fornecidas algumas sugestões importantes:

Como fazer o levantamento bibliográfico? Aqui, acho interessante citar Umberto Eco.

"Ma um bravo studioso sperimentale non comincia a controllare le reazione dei suoi oggeti se prinma non ha fatto almeno um lavoro panoramico (esame degli studi analoghi già compiuti), perché altrimenti rischierebe di spcoprire l'ombrello, di dimostrare qualcosa che è già stato ampiamente dimostrato, o di applicare metodi che si sono dimostrati fallimentari (anche se può essere oggeto di ricerca il nuovo controllo di un metodo che non ha ancora dato risultati soddisfacenti). Quindi una tesi di carattere sperimentale non può essere fatta a casa propria, né il metodo può essere inventato. Anche qui si deve partire dal principio che, se si è un nano intelligente, è meglio saltare sulle spalle di qualche gigante, anche se di altezza modesta; o di un altro nano. C'è sempre tempo in seguito per procedere da soli." [2]

(Tradução - "Um bom pesquisador experimentalista não começa a observar as reaçóes do seu objeto de estudo se antes não fez pelo menos um levantamento bibliográfico panorâmico (exame dos estudos já feitos), porque senão se arriscaria a "descobrir o guarda-chuva" (no Brasil usamos "descobrir a roda"), demonstrar algo que já foi amplamente demonstrado, ou de aplicar métodos experimentais que já se demonstrou serem inválidos (também pode ser objeto de pesquisa o desenvolvimento de um método que ainda não havia dado resultados satisfatórios). Assim, uma tese de caráter experimental não pode ser feita à causa própria, nem o método pode ser inventado. Aqui também deve se partir do princípio que, se és um anão inteligente é melhor saltar sobre os ombros de qualquer gigante, mesmo de altura modesta, ou mesmo de um outro anão. Há sempre a hora certa de prosseguir por conta própria".)

Uma vez definido o tema da pesquisa, tentar delinear as palavras chaves. Há listas de palavras chaves disponíveis nos "sites de internet" das editoras (Elsevier e Wiley, por exemplo).

Fazer um levantamento bibliográfico extenso, englobando tudo o que já foi publicado no assunto, ou relacionado ao assunto. Não é aconselhável restringir a antiguidade do levantamento. Por exemplo: os polímeros condutores intrínsecos só começaram a ser estudados com profundidade a partir da década de 70 do século XX, mas no século XIX já havia relatos da deposição eletroquímica dos produtos da oxidação da anilina e das suas propriedades eletrocrômicas. Isso significa que a pesquisa bibliográfica não deve se limitar aos bancos de dados existentes no momento que o projeto está sendo escrito deve-se usar também o Chemical Abstracts ou outros bancos de dados impressos que revisam os anos anteriores à existência dos bancos de dados informatizados.

Selecionar as publicações mais relevantes, por autor, por conteúdo e, principalmente, por grau de detalhamento da parte experimental. Deve-se dar atenção especial aos trabalhos da área feitos por pesquisadores brasileiros.

Ler as publicações, prestando atenção na parte experimental, nos resultados e discussão e nas conclusões. A primeira vez que nos deparamos com um assunto novo 
é difícil entender tudo o que se publicou, mas nas leituras subseqüentes irá melhorando o entendimento do assunto. Se for o caso, enviar uma mensagem de e-mail ao autor para tirar dúvidas que ainda persistam depois da leitura. Para saber mais sobre a apresentação das Figuras, Gráficos, Tabelas e Bibliografia, ver os itens "Figuras e Tabelas" e "Apresentação da Bibliografia".

\section{Formatação das páginas}

- Usar sempre papel tamanho A4 (é o tamanho padrão em todo o mundo, exceto nos EUA)

- Numerar as páginas (exceção da folha de rosto).

- Margens razoáveis $(2,5 \mathrm{~cm}$ em geral, a não ser que haja uma norma específica).

- Folha de rosto com: título, nome do(s) autor(es), orientador ou supervisor (se houver), local onde o projeto será desenvolvido, mês e ano.

Antes de submeter, ou mesmo antes de escrever o projeto, é interessante consultar o website da instituição para onde se vai remeter o projeto e verificar se o formulário de avaliação que será usado pelo(s) assessor(es) está disponível. Este formulário conterá os pontos que a instituição acha mais importante para serem avaliados. Desta forma será possível enfatizar no projeto estes pontos positivos e evitar aquilo que o órgão de fomento julga negativo.

\section{Relatórios}

Depois que o projeto foi submetido e aprovado e já foi vencida uma etapa da pesquisa, é hora de fazer o primeiro relatório. Antes de faze-lo é bom reler o projeto e verificar em que etapa do cronograma de trabalho está a pesquisa. Depois disso pode-se passar à redação, lembrando que a pessoa que vai ler o relatório já leu o projeto, portanto é desnecessário repetir novamente tudo o que tinha no projeto. Mais especificamente, não há necessidade de repetir toda a introdução e a revisão bibliográfica. No relatório deve-se comentar somente a bibliografia que surgiu depois que o projeto foi redigido (ou alguma que "escapou" na primeira revisão bibliográfica).

Sugere-se observar as seguintes etapas para montar o relatório:

1. Coleta e organização dos dados.

2. Organização das tabelas e figuras.

3. Discussão dos dados com o orientador, supervisor e/ ou com os colegas.

4. Coleta, leitura e atualização da bibliografia.
5. Redação da primeira versão e correção pelo orientador ou supervisor.

6. Redação da versão final.

Abaixo está uma sugestão para a organização do relatório:

1. Folha de rosto.

2. Resumo de, no máximo, uma página do projeto e, se for o caso, do(s) relatório(s) anterior(es).

3. Resumo das atividades do período que abrange o relatório: congressos, publicações, treinamentos técnicos, cursos, disciplinas, monitoria, estágio docente, etc.

4. Objetivos, como apareceu na versão submetida do projeto. Se houver uma mudança de objetivos, esta pode e deve ser justificada nesta seção.

5. Se for o caso, resposta às questões levantadas pelo assessor no parecer do último relatório. $\mathrm{O}$ assessor pode se transformar em um excelente conselheiro se suas sugestões forem sempre acatadas ou rechaçadas com uma boa justificativa. De qualquer forma as sugestões e críticas do assessor não devem passar desapercebidas.

6. Atualização da revisão bibliográfica a partir da época em que foi escrito o projeto ou o último relatório.

7. A Parte Experimental deve conter uma descrição dos experimentos realizados compreendendo:

a. Equipamentos

b. Materiais e reagentes

c. Procedimentos experimentais e métodos de cálculo (a parte experimental não deve conter resultados ou discussão dos mesmos). A descrição dos procedimentos experimentais deve ser feita de modo que uma pessoa com a mesma formação do redator do relatório possa reproduzir os experimentos.

8. Resultados, contendo figuras, tabelas e discussão. Lembrar que primeiro deve-se apresentar e discutir os resultados para depois concluir alguma coisa a partir deles. Em um relatório deve-se incluir também os experimentos que não deram os resultados desejados. Isto será usado para justificar novos experimentos ou uma mudança do projeto e/ou cronograma.

9. Conclusões (parciais ou não).

10. Próximas etapas e cronograma. Aqui também se pode incluir uma justificativa para novas etapas ou para modificações do cronograma original

11. Bibliografia, utilizando a mesma norma usada no projeto.

O relatório deve ser apresentado da melhor forma possível, pois ele reflete a qualidade da pesquisa realizada. 
No caso de relatórios de bolsas de estudo ou de auxílios, também é bom verificar, antes de escrevê-lo, quais os itens serão usados para o seu julgamento pela entidade financiadora da pesquisa. Isso é possível se os formulários a serem usados pelo(s) assessor(es) estiverem disponíveis no website da entidade financiadora da pesquisa. Desta forma será possível fornecer os dados que o(s) assessor(es) irão usar em seu julgamento.

Para saber mais sobre a apresentação das Figuras, Gráficos, Tabelas e Bibliografia, ver os itens "Figuras e Tabelas" e "Apresentação da Bibliografia".

\section{Formatação das páginas.}

- Usar papel tamanho A4 (é o tamanho padrão em todo o mundo, exceto nos EUA).

- Numerar as páginas (exceção da folha de rosto).

- Margens razoáveis (2,5 cm em geral, a não ser que haja uma norma específica).

- Folha de rosto com: título, número do processo, número do relatório, nome do(s) autor(es), orientador ou supervisor (se houver), local onde o projeto está sendo desenvolvido, mês e ano.

\section{Dissertações e teses}

Dissertação é o texto referente a um trabalho final de curso de graduação ou de Mestrado. A Tese se refere ao texto final de um curso de Doutorado ou ao texto submetido para um concurso de Livre-docência.

Devem ser redigidas no instante em que orientador e orientado concordarem que os resultados alcançados na pesquisa são coerentes com os objetivos colocados no projeto inicial. Não existem normas para redação destes textos, cada grupo ou cada curso tem o seu método. No entanto, algumas características comuns têm que ser seguidas, tais como: resumo, introdução, objetivos, parte experimental, resultados e discussão, conclusões e bibliografia. Em alguns cursos aceita-se as publicações em periódicos como parte constituinte da Tese, mas isso ainda não é uma prática comum. Algumas vezes a Tese é dividida em capítulos independentes, mas isso depende diretamente da coerência da pesquisa a ser relatada e deve ser cuidadosamente discutido com o orientador antes de iniciar a redação. Neste caso, cada capítulo deve ter uma breve introdução especificando o assunto, parte experimental, resultados e discussão e conclusões.

A Dissertação ou a Tese deve ainda conter uma lista das abreviações usadas no decorrer do texto, uma listagem das figuras e das tabelas com as respectivas páginas onde aparecem e um curriculum vitae resumido do autor. Abaixo discute-se todas estas seções ou capítulos de uma Dissertação ou Tese.

\section{- Lista de abreviações:}

Nesta deve-se colocar todos os acrônimos que foram criados ou usados ao longo do texto, como por exemplo, NMR - ressonância magnética nuclear, LDPE - polietileno linear de baixa densidade, etc. Os símbolos de unidades do sistema internacional de medidas não precisam ser incluídos nesta lista, assim como as abreviações de kilo (com k minúsculo!), mega, etc. É praxe utilizar os acrônimos mais comuns na literatura (e.g. os de língua inglesa) mas, independente disso, tentar usar todos da mesma língua, por exemplo RMN e PEBD ou NMR e LDPE.

\section{- Resumo e "abstract":}

Devem conter, em uma página, uma pequena introdução sobre o assunto, um comentário breve sobre a metodologia e as principais conclusões que corroboram a(s) hipótese(s) levantada(s). O "abstract" deve ser fiel ao resumo em português.

\section{- Introdução:}

Esta pode ser subdividida em diversas sub-seções para facilitar a sua leitura. Ela deve conter a problemática estudada e uma visão geral e completa do "estado da arte" no assunto da Tese ou Dissertação. Uma curta visão histórica da pesquisa é as vezes interessante antes de se começar a discutir a bibliografia em ordem cronológica. $\mathrm{Na}$ introdução deve ser citada a bibliografia mais importante referente ao trabalho. Deve-se evitar a repetição de modelos, teorias e métodos descritos em livros textos. A introdução não deve ser muito extensa nem muito curta (a ênfase do trabalho deve ser o que foi feito pelo autor e não pelos seus antecessores). Deve-se também situar o trabalho no contexto atual e cronológico dos trabalhos de pesquisa do grupo, do orientador e/ou da instituição. As figuras, reações, equações ou esquemas que forem copiadas da bibliografia devem conter a citação bibliográfica em sua legenda. Estas devem ser numeradas em seqüência.

\section{- Objetivos:}

Deve conter de forma concisa os objetivos do trabalho, ou seja, as hipóteses que se quer demonstrar, os dispositivos que se quer montar, os compostos que se deseja sintetizar, etc. Também deve-se dar, de forma concisa, as razões pelas quais se quer atingir 
estes objetivos. Não basta dizer que essa pesquisa é inédita porque nunca foi feita (provavelmente, ninguém nunca pesquisou porque os cavalos não acasalam com as borboletas, isso seria uma pesquisa inédita?), é preciso justificar a pesquisa com base no conhecimento científico existente. Estes devem estar baseados nas informações fornecidas na Introdução.

\section{- Parte experimental ou metodologia:}

Esta parte da Dissertação ou Tese deve descrever os materiais, reagentes e equipamentos usados no trabalho. Deve também conter a descrição de todos os experimentos cujos resultados serão discutidos a seguir. Este capítulo não deve conter comentários e resultados. Os experimentos devem ser descritos da forma mais resumida e precisa possível. A sua descrição deve ser de tal forma que, qualquer pesquisador com a mesma formação do autor seja capaz de repetir os experimentos. Deve-se usar tabelas para resumir condições experimentais de grupos de experimentos feitos dentro de uma determinada programação estatística. A descrição dos experimentos não precisa seguir a ordem cronológica em que eles foram feitos, mas deve seguir uma ordem lógica dentro dos objetivos do trabalho. Em uma Dissertação ou Tese pode-se incluir também os experimentos que não deram os resultados desejados. Deve-se evitar uma excessiva divisão em sub-seções e a repetição do título da seção no texto, e.g., se a seção trata dos "Espectros de FTIR", o primeiro parágrafo deve começar com: "Estes espectros foram medidos..." e não com "Os espectros de FTIR foram medidos ...”.

\section{- Resultados e Discussão:}

Neste capítulo serão apresentados e discutidos os resultados obtidos no decorrer dos trabalhos. Os dados devem ser organizados na forma de Tabelas e Gráficos, que deverão ser numerados em seqüência ao longo do capítulo ou do texto. Veja no ítem "Figuras e Tabelas" algumas dicas para a sua confecção. Os resultados também não precisam ser apresentados na ordem cronológica em que foram obtidos, eles devem ser apresentados de forma a fornecer subsídios para confirmar a hipótese que se quer demonstrar no trabalho. Aqui também se deve evitar um número excessivo de sub-seções.

\section{- Conclusões:}

Como diz o nome, a conclusão é para concluir. Ela não deve ser um resumo do que foi dito nas seções anteriores, mas uma conclusão do trabalho demonstrando que os objetivos foram (ou não) alcançados e que as hipóteses que se queria demonstrar foram demonstradas. Este capítulo também pode ser bem curto; às vezes não tem mais que uma página.

Abaixo dou uma sugestão de etapas para a redação de uma Dissertação ou Tese:

i. Consolidação do primeiro rascunho do trabalho completo com figuras, tabelas e bibliografia (ver ítem "Figuras e Tabelas"). Sugiro começar a redação pela parte mais fácil, a Parte Experimental; depois escrever os Resultados e Discussão, a Introdução e, por último as Conclusões. O Resumo e Abstract e os Objetivos podem ser escritos por último. A bibliografia deve ser colocada à medida que o texto vai sendo escrito. Se deixar para depois será impossível achar de novo o lugar onde se queria citar um determinado autor. Depois de pronto o primeiro rascunho, entregar o texto ao orientador para a primeira leitura.

ii. Fazer as correções no primeiro rascunho. Depois da correção, imprimir uma cópia e deixar o texto "hibernando" por, pelo menos, uma semana. Também é interessante pedir a um colega da área para ler o texto e sugerir correções. Desaconselho usar um "especialista" em correções gramaticais, pois eles geralmente são da área de Ciências Humanas e dominam um tipo de linguagem e vocabulário muito diferente da área de Exatas.

iii. Leitura de todo o texto, novas correções (serão muitas). Conferir a numeração seqüencial de figuras, tabelas, equações e bibliografia. Leitura final feita pelo orientador. (mais correções!)

iv. Correções finais, impressão da versão final e cópias para a banca examinadora. Mesmo depois de todas estas etapas, o texto nunca estará livre de conter alguns erros; afinal é preciso deixar algum serviço para a banca!

v. Depois disso é necessário preparar a apresentação que será feita no dia da Defesa.

Cada curso de pós-graduação tem suas normas específicas para a impressão da versão final corrigida e defendida das Teses e Dissertações. Estas normas devem ser seguidas à risca senão o título correspondente à Tese ou Dissertação não será homologado.

Para saber mais sobre a apresentação das Figuras, Gráficos, Tabelas e Bibliografia, ver os itens "Figuras e Tabelas" e "Apresentação da Bibliografia".

\section{Formatação das páginas}

- Usar papel tamanho A4 (é o tamanho padrão em todo o mundo, exceto USA). Na Unicamp a versão final é feita em papel tamanho letter porque os equipamentos 
da gráfica só operam com esse tamanho de papel.

- Numerar as páginas (exceção da folha de rosto).

- Margens razoáveis $(2,5 \mathrm{~cm}$ em geral, a não ser que haja uma norma específica).

- Folha de rosto com: título, nome do autor, do orientador, co-orientador (se houver), instituição onde a Tese ou Dissertação foi desenvolvida e ano.

\section{Comunicações em congressos}

Apresentar trabalhos e/ou comunicações em congressos científicos é uma forma de divulgar os resultados de uma pesquisa e também uma oportunidade para discutir estes resultados com pessoas de outros grupos de pesquisa e de outras instituições. Hoje em dia há uma pletora de congressos em todas as áreas, é preciso ter muito critério para selecionar o congresso mais adequado para a apresentação de um trabalho. Deve-se sempre pensar no público alvo do congresso e não na qualidade das praias do local onde o congresso será realizado. Abaixo algumas sugestões para este procedimento.

\section{- Etapas para redigir uma comunicação para um congresso:}

1. Verificar o assunto do congresso, o tipo de audiência dos trabalhos, o local onde será realizado, a possibilidade de comparecer e as datas limites (em inglês isso tem um nome muito sugestivo: dead line) para inscrição, submissão de resumos, pagamento de inscrição com desconto, reserva de hotel, etc.

2. Reunir os resultados e verificar se constituem um conjunto coerente, com começo, meio e fim e dentro do escopo do congresso ou da seção do congresso onde se pretende apresentar o trabalho.

3. Definir o conjunto dos autores do trabalho. O autor principal (quem "carregou o piano") geralmente está em primeiro lugar e o orientador deve vir em último lugar, mas isso não é uma regra geral. Alguns congressos têm normas específicas para isto que devem ser respeitadas.

4. Ler atentamente as instruções para a redação da comunicação, prestando atenção à limitação de tamanho, tamanho de letra, etc.

5. Definir um título que dê a exata noção do que será apresentado, evitando títulos extensos demais e abreviações. O título não deve ser um resumo do trabalho. O título deve despertar a curiosidade dos participantes do congresso. A elaboração do título é um exercício de marketing.
6. Redigir a comunicação de modo que ela contenha: introdução, objetivos, parte experimental, resultados e discussões e conclusões. Não deve haver sub-títulos indicando estas seções, a não ser que as normas específicas do congresso o exijam. De um modo geral, a comunicação toda é escrita em um único parágrafo, a não ser que as normas do congresso estabeleçam o contrário.

7. Incluir figuras, tabelas, esquemas de reações e fórmulas somente quando o espaço permitir e com dimensões que permitam a sua visualização quando o livro de resumos for impresso ou quando for impresso a partir do CD com os textos do congresso.

8. Não usar cores, pois os livros de resumos são sempre impressos em preto e branco. Se o resumo for gravado em $\mathrm{CD}$, consultar os organizadores ou ler as instruções atentamente para verificar se é permitido usar cores.

9. Agradecer às entidades que financiaram o trabalho, doaram os reagentes e cederam os equipamentos e as pessoas que auxiliaram nas medidas e/ou interpretações. Algumas agências de fomento exigem que se coloque o número do processo junto com o nome do beneficiado e a sigla da agência.

10. Citar a bibliografia seguindo as normas explícitas para o resumo e definidas pelos organizadores do congresso. Sempre que possível, citar autores brasileiros.

11. Verificar se o texto cabe no template fornecido pelos organizadores para a submissão on-line, se for o caso.

12. Quando a submissão do trabalho for feita por vias convencionais, correio, isso deve ser feito com a antecedência necessária para o trabalho chegar no destino antes da data limite. No caso da submissão on line, enviar o resumo antes da data limite para evitar o congestionamento do servidor de rede da instituição organizadora. Como todos nós sabemos, é exatamente duas horas antes de expirar este prazo que: acaba a força no prédio, cai a rede, falta tinta no cartucho, "dá pau no computador", "dá pau no Windows", etc. Tente "enganar o Murphy" enviando o trabalho com antecedência.

- Etapas pelas quais passa a apresentação de uma comunicação em Congresso:

1. Leitura atenta das normas para submissão.

2. Redação da comunicação segundo as normas específicas para o Congresso.

3. Envio da comunicação dentro do prazo e, se 
for o caso, junto com a inscrição no congresso e respectivo pagamento. Atualmente, a maioria dos congressos aceita somente o envio on-line, portanto deve-se tomar atenção redobrada com os procedimentos de envio e o tipo de programa que será usado para redigir o texto e inserir figuras e tabelas.

4. Recebimento da confirmação que o trabalho chegou às mãos da comissão organizadora.

5. Recebimento da carta ou e-mail de aceitação ou rejeição da comunicação. Poucos congressos pedem versão revisada de comunicações curtas. Alguns congressos solicitam nesta etapa uma versão completa do trabalho para ser publicada em um livro de Anais ou em uma edição especial do periódico da Sociedade que está organizando o congresso. Verificar se isto é uma condição para o trabalho ser apresentado.

6. Confecção do painel ou da apresentação oral. No caso de painel, verificar as normas de tamanho e de lay-out. As apresentações orais usando projetor multimídia ("data-show") e computador só devem ser preparadas após verificar a disponibilidade desta ferramenta no congresso. Mesmo assim, recomenda-se levar o próprio note-book para evitar incompatibilidades de programas e de equipamentos. Se não houver projeto multimídia, preparar transparências para usar com retro-projetor (overhead projector). Alguns pesquisadores mais precavidos levam aos congressos o seu notebook e as transparências impressas. Não recomendo utilizar slides porque muitos lugares já não dispõem de projetor de boa qualidade e eles requerem uma sala muito escura.

7. Ensaiar a apresentação oral para verificar se está dentro do tempo estipulado para a mesma. Geralmente se calcula 1 minuto por slide ou transparência. Conferir o painel antes de imprimilo. Em ambos os casos, são recomendados um período de hibernação antes de fazer as correções e impressão final.

8. Imprimir o painel ou as transparências com a devida antecedência. Recomenda-se imprimir cópias do painel em tamanho A4 para distribuir durante a seção de apresentação do mesmo para as pessoas interessadas no trabalho.

9. Viajar para o congresso levando o material da apresentação na "bagagem de mão". A roupa pode ser perdida, mas o trabalho tem que chegar ao destino junto com o seu apresentador.

10. No horário de início da seção onde será apresentada a comunicação oral, apresentar-se ao coordenador.
Levar seu próprio apontador. Devem-se seguir rigorosamente as instruções para as apresentações orais; com relação ao tempo de apresentação, ao tempo para as perguntas e o horário de entrega do CD com o arquivo da mesma.

11. No caso de painel, afixá-lo no local previsto no horário indicado pelos organizadores do congresso. Comparecer pessoalmente à seção, munido de cartões de visita, anotar as perguntas e recolher os cartões das pessoas que visitarem o painel. Levar o material para fixar o painel (geralmente usa-se fita adesiva dupla-face).

12. Após retornar do congresso enviar separatas para as pessoas que se interessaram pelo trabalho e manter a comunicação com elas via e-mail.

13. Procurar publicar o trabalho completo o mais rápido possível, já que muitas pessoas tomaram conhecimento dele e poderão fazer a mesma coisa.

Depois de retornar do congresso não esquecer de escrever o relatório da participação no mesmo para enviar à agência de fomento que financiou a viagem. De um modo geral, este relatório deve descrever a sua participação no congresso com: uma avaliação da qualidade do mesmo, uma descrição das conferências mais importantes, o tipo de impacto causado pelo seu trabalho e as discussões e as dúvidas levantadas durante a sua apresentação.

Para saber mais sobre a apresentação das Figuras, Gráficos, Tabelas e Bibliografia, ver os itens "Figuras e Tabelas" e "Apresentação da Bibliografia".

\section{Publicações}

Uma publicação deve ser redigida quando o trabalho experimental atingir uma etapa de maturidade que corresponda ao atendimento da meta ou de uma das metas da pesquisa proposta. Deve-se possuir um conjunto de resultados experimentais (ou teóricos) que constituam uma unidade e comprovem uma hipótese levantada durante uma determinada etapa da pesquisa. Ela não deve visar somente o ato de publicar, mas deve visar a divulgação de um resultado que será útil para a comunidade científica de um modo geral. $O$ texto da publicação deve ser objetivo e conciso. Aqui vale a pena citar uma frase de Schrödinger:

"If you cannot, in the long run, tell everyone what you have 


\section{been doing, your doing has been worthless" [3]}

(Tradução: Se você não puder dizer a todos, a longo prazo, o que você está fazendo, então o que você está fazendo é inútil).

\section{Etapas sugeridas para redigir uma publicação:}

1. Escolha do periódico adequado para a divulgação dos resultados. Devem ser levados em consideração: o público que o periódico atinge e o seu índice de impacto. Também lembrar que as "avaliações de produtividade acadêmica" levam em conta o nível de exigência do corpo editorial da revista, além do índice de impacto.

2. Ler cuidadosamente o "expediente" do periódico para conhecer os seus objetivos. Também se deve verificar se o periódico cobra para publicar. Todas estas informações estão no website da editora na internet.

3. Verificar se o periódico está disponível na biblioteca da instituição ou pode ser acessada via internet. Verificar a forma de divulgação do mesmo (impressa, $\mathrm{CD}$, internet?)

4. Leitura de uma publicação neste periódico, em assunto relacionado ao que se pretende submeter o trabalho.

5. Leitura atenta das normas para redação dos trabalhos no periódico escolhido, prestando atenção nos seguintes pontos:

o Tamanho do resumo.

- Número de palavras chave.

- Tipos de seções em que a publicação deve ser dividida, além da ordem de apresentação sugerida para as mesmas.

- Forma de citação bibliográfica (cada periódico tem normas específicas, sempre diferentes umas das outras!).

- Forma de colocar figuras e tabelas.

- Limitação da extensão da publicação. Muitos periódicos limitam o número de páginas dos trabalhos a serem publicados.

- Idioma a ser usado (português, inglês USA, inglês britânico?). Símbolos e outras unidades a serem usados. Consultar as listas de expressões que devem ser evitadas [4-6].

- Número de cópias a ser enviado para submissão do trabalho, tamanho do papel, formatação da página, etc. As normas de publicação geralmente saem uma vez por ano no próprio periódico ou podem ser consultadas no website da editora na internet.

6. Definição do título e dos co-autores. Valem as mesmas observações feitas para as comunicações em congressos.

7. Organização dos resultados experimentais em figuras e tabelas. É bom lembrar que a maioria dos periódicos recomenda aos árbitros verificar se todas as tabelas e figuras são necessárias para a compreensão do trabalho. Portanto é bom se ater ao mínimo necessário.

8. Organização da bibliografia relevante.

9. Redação do primeiro rascunho já no idioma em que o trabalho vai ser publicado (ver na próxima seção o que o trabalho deve conter).

10. Leitura e correção do rascunho pelos outros coautores.

11. Redação da versão final e período de "hibernação".

12. Correção do idioma por um colega ou "ghost writer". Tomar muito cuidado com os corretores ortográficos automáticos que podem induzir muitos erros grosseiros (por exemplo: as palavras below (abaixo) e bellow (mugir), ou cooper (nome de um exercício físico) e copper (cobre), seção e sessão, serão consideradas corretas pelo corretor ortográfico do editor de texto).

13. Redação da versão final na forma como o trabalho vai ser submetido.

\section{O trabalho a ser submetido deve conter [5]:}

- Um título que dê a exata noção do que será apresentado, evitando títulos extensos demais e o uso de abreviações ou acrônimos.

- Lista de autores com o endereço do(s) local(ais) onde foi feita a pesquisa. A correspondência entre autores e endereços deve ser indicada por símbolos, para não confundir com a bibliografia. É importante lembrar que o(s) endereço(s) que vai(ão) no cabeçalho do trabalho se refere(m) especificamente ao(s) local(ais) onde o trabalho foi desenvolvido. Dependendo do periódico, se algum dos autores vem de outra instituição, o seu endereço funcional ou de origem deve ser colocado como nota de rodapé (em algumas revistas aparece como: present address ou on leave from, etc).

- Resumo: contendo todos os elementos para entender os objetivos do trabalho e as metas alcançadas. Deve incluir um sumário das conclusões. Deve-se evitar abreviações e/ou acrônimos, pois o resumo aparecerá de forma isolada em diversos lugares e o leitor não terá acesso ao significado destas abreviações.

- Introdução: contendo uma revisão do assunto e abrangendo a maior parte possível da literatura, citando os primeiros autores a trabalhar naquele assunto e procurando citar os trabalhos feitos por cientistas brasileiros da área. A introdução de uma publicação deve ser completa, mas concisa. No final da introdução deve-se descrever, em um único parágrafo, os objetivos do trabalho, ou seja, a hipótese a ser demonstrada.

- Parte experimental: contendo uma descrição 
detalhada dos procedimentos usados no laboratório. Um trabalho científico só é reconhecido como tal se for reprodutível e, para ser reprodutível, tem que ter uma parte experimental que possa servir de roteiro para qualquer outro químico em qualquer lugar do mundo poder reproduzir os experimentos descritos.

- Resultados e discussão: contendo uma descrição dos resultados, figuras e tabelas, e a discussão dos mesmos. Lembrar sempre que a conclusão da discussão deve vir depois dos resultados.

- Conclusões: de forma concisa concluir se a hipótese levantada ao final da introdução foi confirmada e comentá-la. Deve-se evitar dizer que esta conclusão será confirmada em um próximo trabalho (o editor recusará o trabalho e recomendará incluir nesta publicação os resultados que seriam colocados no próximo trabalho).

- Agradecimentos: incluir as entidades que financiaram as bolsas de estudo, a compra dos equipamentos, a doação de reagentes ou materiais e as pessoas que contribuíram direta ou indiretamente para o trabalho. Os co-autores não devem constar dos agradecimentos.

- Bibliografia: deve ser listada da forma como consta nas instruções para publicação no periódico escolhido.

- Legendas das figuras em página(s) separada(s).

- Tabelas (uma por página).

- Figuras (uma por página). Ver a lista de símbolos que podem ser usados nas figuras, sugeridos pela editora do periódico.

\section{Como organizar o material para enviar ao editor e submeter o trabalho para publicação:}

Cada periódico tem as suas normas específicas, que devem ser consultadas antes de se iniciar a redação do trabalho. No entanto, alguns itens organizacionais são comuns a muitos periódicos e serão descritos abaixo.

- Primeira página contento: título, nome dos autores, local(ais) onde a pesquisa foi realizada, resumo, palavras chave e indicação do autor para onde a correspondência deve ser enviada (corresponding author). Se for o caso, incluir no rodapé o(s) endereço(s) $\mathrm{do}(\mathrm{s})$ autor(es) que não correspondem ao(s) endereço(s) onde foi realizada a pesquisa.

- Texto do trabalho na ordem sugerida pelas instruções do periódico escolhido. $\mathrm{Na}$ maioria das vezes eles adotam a ordem: introdução, parte experimental, resultados e discussão, conclusões e agradecimentos.

- Referências bibliográficas, listadas de acordo com as normas do periódico.

- Legendas das figuras em uma ou mais páginas separadas.
- Tabelas, uma por página.

- Figuras, uma por página.

- Todas as páginas devem ser numeradas.

- Deve-seincluirtambémumacartadeencaminhamento endereçada ao editor-chefe ou ao editor regional da revista, de acordo com as instruções. Alguns editores aceitam sugestões de árbitros para a avaliação do trabalho.

\section{A publicação de resultados técnico-científicos passa por uma verdadeira "via sacra":}

1. Redação e correção do texto (ver acima).

2. Submissão ao editor do periódico com uma carta de encaminhamento. Algumas revistas aceitam a submissão on-line ou por e-mail. Alguns editores aceitam sugestões de nomes de pesquisadores para atuar como árbitro (referee).

3. Recebimento do aviso (por carta ou e-mail) que o trabalho chegou às mãos do editor.

4. Recebimento da carta (ou e-mail) de: i) rejeição (ler atentamente o parecer dos árbitros para ver os erros que cometeu), ii) aceitação com correções (ler atentamente as críticas e sugestões dos árbitros e corrigir o texto de acordo com elas) ou iii) aceitação direta sem correções (parabéns, isso é raro, você deve abrir uma garrafa de vinho tinto de boa procedência e tomá-la até o fim junto com os outros co-autores para comemorar; é permitido abrir outras garrafas em seqüência).

5. Envio da versão corrigida na forma impressa e no número de cópias solicitado pelo editor em sua carta. Colocar no rodapé das páginas e junto com a numeração o seguinte texto "first revised version" (para trabalhos em inglês). $\mathrm{Na}$ carta de encaminhamento listar as correções feitas, indicando a página e o número da linha contado de cima para baixo. Alguns periódicos pedem uma resposta separada para cada um dos pareceres. Estas devem ser enviadas ao editor com uma carta de encaminhamento. É recomendável agradecer as sugestões e correções feitas pelos árbitros (afinal eles tiveram o trabalho de ler o trabalho todo e corrigi-lo!). A maioria dos periódicos pede que se envie um disquete ou $\mathrm{CD}$ com a versão final do arquivo gerado pelo editor de texto usado para produzir $\mathrm{o}$ artigo. Verificar se o texto e as figuras devem ir juntos ou em arquivos separados. $\mathrm{O}$ disquete ou $\mathrm{CD}$ deve ser identificado segundo as normas da editora do periódico. A versão impressa deve corresponder fielmente à versão digital, pois é a versão digital que vai ser usada para a editoração final.

6. Recebimento da carta (ou e-mail) de aceitação final (comemore com moderação), indicando que o artigo foi encaminhado para a editoração final e gráfica. 
Nesta etapa você já pode colocar esta publicação no seu curriculum vitae com a observação "aceito".

7. Recebimento das provas tipográficas solicitando resposta o mais rápido possível. Atualmente elas vêm em formato *.pdf, como "attachment" de um email, e podem ser impressas no computador. Faça as correções à mão e envie a listagem das correções feitas por e-mail, fax ou por correio aéreo normal. Nesta etapa só é permitido corrigir os erros tipográficos, nenhum material novo pode ser incluído. Prestar muita atenção nas fórmulas e nas legendas das tabelas e das figuras. Envie também o termo de cessão dos direitos de copyright e a folha de compra de separatas (se for o caso). Âs vezes cada uma destas vai para um endereço diferente. Nesta etapa você já pode colocar esta publicação em seu curriculum vitae com a observação "no prelo".

8. Alguns periódicos enviam nesta etapa um e-mail aos autores dizendo que a versão final do artigo foi enviada para a gráfica. Outros já disponibilizam o artigo em sua webpage antes de sair a versão impressa.

9. Publicação propriamente dita. Após esta etapa o artigo pode constar no curriculum vitae com a referência completa.

10. Recebimento das separatas pelo correio. Distribua as separatas pelos co-autores e envie algumas pelo correio para pessoas que trabalham na mesma área. Registre a publicação nos bancos de dados de sua instituição e no currículo Lattes.

Para saber mais sobre a apresentação das Figuras, Gráficos, Tabelas e Bibliografia, ver os itens "Figuras e Tabelas" e "Apresentação da Bibliografia".

\section{Formatação das páginas}

- Usar papel tamanho A4, a não ser que as normas da revista especifiquem outro tamanho, e imprimir de um só lado.

- Numerar as páginas (exceção da folha de rosto), inclusive as páginas com as legendas, tabelas e figuras.

- Margens razoáveis (2,5 cm em geral), a não ser que haja uma norma específica.

- Alguns periódicos pedem uma folha de rosto com: título do trabalho e endereço dos autores.

- Verificar o número de cópias que devem ser enviadas e se há necessidade de enviar disquete ou CD com o arquivo gerado pelo editor de texto usado.
Figuras e tabelas

\section{Apresentação das figuras:}

Como figura, entendemos os desenhos (estruturas, fluxogramas, esquemas de reações, esquemas de aparelhos, diagramas, etc), fotos digitais ou analógicas e gráficos. Elas devem ser todas denominadas figuras para evitar a presença de diversas seqüências de numeração. Todas devem ser numeradas e tem que conter uma legenda. Fora desta categoria poderíamos colocar somente as equações matemáticas, que também devem ser numeradas em seqüência. No caso de Teses ou Dissertações, a numeração das figuras pode acompanhar a numeração dos capítulos, para facilitar a sua localização, por exemplo, a segunda figura do terceiro capítulo seria numerada Figura III.2. Abaixo algumas sugestões para a elaboração das figuras:

- Os desenhos devem ser feitos de modo a ilustrar claramente a idéia que se quer passar, evitandose formas rebuscadas, excesso de cores e layout complicado. Existem diversos programas de computador para elaborar desenhos (e.g. o Corel Draw), mas as vezes um desenho feito a mão pode ser mais simples e ilustrativo. As estruturas químicas e reações podem ser feitas usando o ChemWindow (BioRad Informatics Division; representante no Brasil: http://www.eccen.com.br/biorad). Em todos os casos, cada figura deve ter uma legenda. É necessário dar a referência bibliográfica se a figura for a reprodução de uma já publicada. A maioria das revistas requisita uma permissão de publicação da editora do periódico que originalmente publicou a figura. Essa permissão tem que ser solicitada pelos autores do trabalho. No caso de textos escritos em português, deve-se traduzir a legenda dos eixos dos gráficos e os textos que estiverem na figura. Ao fazer isso, ficamos isentos da necessidade de pedir autorização de publicação para a editora do periódico que publicou a figura originalmente, porém é necessário dar a referência bibliográfica.

- O gráfico é a representação matemática de uma variável em função de outra(s). Como tal deve seguir as normas da matemática. Deve-se usar linhas visíveis, escala real (não existe tempo negativo ou número fracionário de tentativas e de indivíduos), evitar cores, colocar as barras de erro, só ligar os pontos se estes representarem uma função matemática, colocar uma escala legível e condizente com o número de algarismos significativos da medida, colocar as unidades de forma inteligível e usando sempre o sistema internacional de unidades, sistema SI, e seus símbolos. Por exemplo, não usar concentração molar 
e sim mol $\mathrm{dm}^{-3}$. Há uma regra simples; todas as unidades cujos nomes derivam de nomes de cientistas são abreviadas com letras maiúsculas, por exemplo: volt $=\mathrm{V}$ (de A. Volta), ampère = A (de Ampère), Newton $=\mathrm{N}$ (de I. Newton), etc. As outras unidades são sempre em letras minúsculas, como segundo $=\mathrm{s}$. É bom lembrar que símbolo não tem plural, portanto quilômetros será sempre abreviado $\mathrm{km}$ e não kms (como aparece em alguns sinais de transito pelas estradas brasileiras!).

- As legendas devem ser numeradas em seqüência, dando todos os detalhes para se entender a figura sem ler o texto, mas sem ser muito extensa. Os significados dos símbolos usados na figura devem ser colocados na legenda e não no corpo da figura. A legenda deve conter todas as informações a respeito da figura de modo que ela e a figura formem um corpo independente do texto.

- A legenda deve ser alinhada com as margens do texto.

- Centralizar a figura e ajustar o tamanho para que seja visível e compreensível.

Em seguida são mostrados dois exemplos de gráficos, figuras 1 e 2 . Eles representam os resultados de um mesmo experimento (os dados foram graficados a partir de uma tabela do trabalho: F.F. Pereira, C.M.C. Bonelli, A. Elzubair e J.C.M. Suarez, Anais do 70 Congresso Brasileiro de Polímeros, Belo Horizonte, 2003, págs. 113 e 114). Na Figura 1 o gráfico aparece exatamente como é gerado pelo programa Origin. O programa gera o gráfico com uma série de defeitos: a escala do eixo $\mathbf{x}$ contem valores de dose negativos (isto é impossível!), os pontos resultantes das medidas experimentais foram unidos por uma linha cheia sem considerar o desvio ou o erro experimental da medida e os eixos não apresentam as unidades das variáveis representadas.

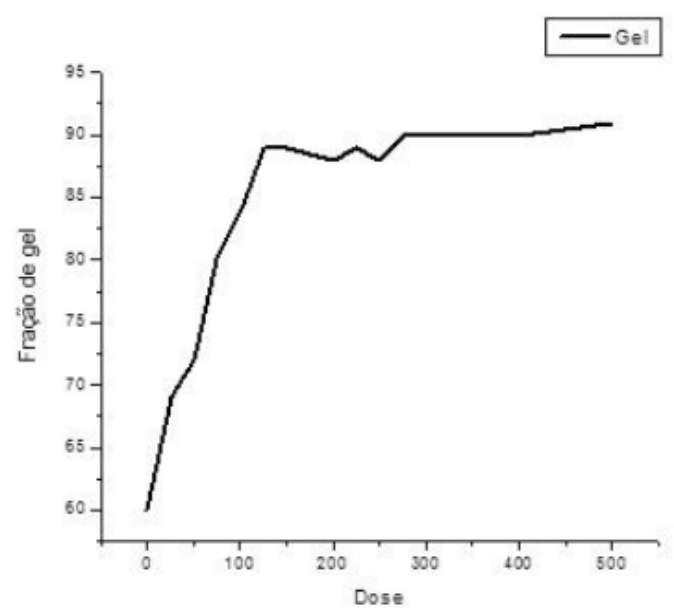

Figura 1 - Variação da fração de gel com a dose de irradiação.
No gráfico da Figura 2 foram feitas as correções: a escala foi ajustada de modo que o eixo $\mathbf{x}$ começa em zero e o eixo y está dentro da faixa de variação da variável fração de gel. O ajuste feito no eixo y é aceitável para se ter uma melhor visão da variação dos resultados dentro de uma determinada faixa. Na figura 2 os pontos experimentais não foram unidos porque eles apresentam uma flutuação dentro do erro experimental e não dispomos das barras de erro para calcular e traçar a melhor curva que conecta estes pontos. De qualquer forma, a figura 2 é válida para representar estes resultados experimentais porque ela mostra claramente que a fração de gel aumenta rapidamente com a dose até $120 \mathrm{kGy}$ e depois não varia mais, independentemente do aumento da dose de irradiação. As legendas destas figuras também procuram exemplificar a melhor maneira de redigir uma legenda. Note-se que UHMWPE é a sigla usada para polietileno de ultra-alta massa molar.

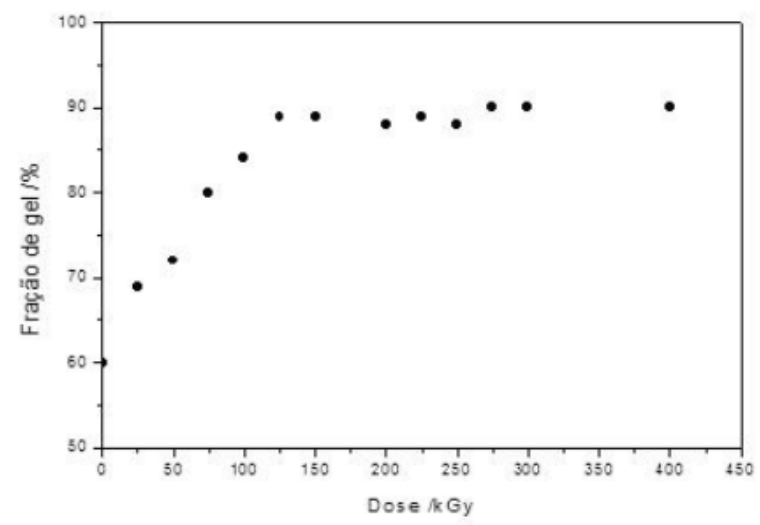

Figura 2 - Variação da fração de gel de uma amostra de UHMWPE em função da dose de radiação gama.

\section{Apresentação das tabelas.}

A tabela é uma forma resumida de apresentar condições ou resultados experimentais. Ela deve ser sempre organizada de forma compreensível para quem não conhece o trabalho. A legenda também deve conter informações que permitam a compreensão da tabela sem a leitura do texto. Abaixo algumas sugestões para confeccionar tabelas:

- Organizá-las de modo a conter o maior número possível de dados de forma compreensível, mas sem exagerar o número de colunas ou linhas.

- Usar o mínimo possível de traços, evitar cores, colocar os desvios, número de algarismos significativos condizente com a medida, colocar as unidades de forma inteligível e usando os símbolos do sistema SI.

- As legendas devem ser numeradas em seqüência, dando todos os detalhes para se entender a tabela sem ler o texto, mas sem ser muito extensa. Especificar na legenda se os resultados foram feitos em replicata, duplicata ou triplicata. 
- A legenda deve ser alinhada com as margens do texto.

- Centralizar a Tabela e ajustar o tamanho para que seja o mais legível possível.

A “Table 1", abaixo, é um exemplo de como se pode reunir em uma só tabela as condições de preparação de uma amostra e os resultados de uma medida de caracterização com estas amostras [7].

Table 1. Composition and electrical conductivity data for Pani-DBSA/O-MMT clay nanocomposites.

\begin{tabular}{|l|c|c|c|l|}
\hline \multirow{2}{*}{ Compound code } & \multicolumn{3}{|c|}{} & \multirow{2}{*}{ Conductivity/(S cm $\left.{ }^{-1}\right)$} \\
\cline { 2 - 5 } & Aniline & O-MMT1 & O-MMT2 & \\
\hline Pani-DBSA & -- & -- & -- & $0.60 \pm 0.15$ \\
\hline Pani-DBSA/O-MMT1 - I & 1 & 2 & -- & $0.12 \pm 0.01$ \\
\hline Pani-DBSA/O-MMT1 - II & 1 & 3 & -- & $0.22 \pm 0.07$ \\
\hline Pani-DBSA/O-MMT1 - III & 1 & 4 & -- & $0.09 \pm 0.01$ \\
\hline Pani-DBSA/O-MMT2 - I & 1 & -- & 2 & $0.36 \pm 0.04$ \\
\hline Pani-DBSA/O-MMT2 - II & 1 & -- & 3 & $0.49 \pm 0.04$ \\
\hline Pani-DBSA/O-MMT2 - III & 1 & -- & 4 & $0.24 \pm 0.02$ \\
\hline
\end{tabular}

A Tabela 1 exemplifica os resultados em paralelo de um conjunto de medidas e a média final. Ela representa um modo de apresentar resultados de forma resumida, contendo: nome da amostra, identificação, resultados de cinco medidas em paralelo e a média aritmética com o desvio. A média dá uma idéia precisa da exatidão da medida. A variação do valor medido está na casa dos décimos de grama apesar das pesagens terem sido feitas em balança analítica com precisão de décimos de miligrama [8].

Tabela 1. Valores e a média de MFI, em g/10 min, referentes a cada amostra.

\begin{tabular}{|l|l|l|l|l|l|l|l|}
\hline Amostra & Identificação & $\mathbf{1}^{\mathbf{a}}$ Leitura & 2 $^{\text {a }}$ Leitura & 3 $^{\mathbf{a}}$ Leitura & 4$^{\text {Leitura }}$ & 5 $^{\text {Leitura }}$ & Média \\
\hline 796/04 & Makrolon & 12,60 & 12,20 & 12,20 & 12,00 & 12,40 & $12,3 \pm 0,2$ \\
\hline 667/04 & Calibre 1080 & 71,77 & 71,03 & 69,85 & 72,04 & 71,52 & $71,2 \pm 0,9$ \\
\hline 682/04 P01 & Calibre 1080 & 65,47 & 63,70 & 65,67 & 66,49 & 63,52 & $65 \pm 1$ \\
\hline 682/04 P02 & Calibre 1080 & 67,56 & 68,05 & 66,93 & 69,31 & 68,42 & $68,1 \pm 0,9$ \\
\hline 743/04 P01 & LS1-111 & 11,86 & 12,12 & 11,88 & 11,80 & 11,92 & $11,9 \pm 0,1$ \\
\hline 743/04 P02 & LS1-111 & 11,92 & 12,16 & 11,80 & 11,84 & 11,94 & $11,9 \pm 0,1$ \\
\hline
\end{tabular}

Os exemplos de figura e tabela foram dados somente para se ter uma idéia da melhor maneira de elaborá-los, sempre é com contar com uma certa dose de bom senso.

\section{Apresentação da bibliografia}

Abaixo alguns comentários sobre como se deve citar e chamar a bibliografia no texto.

As citações bibliográficas podem aparecer em ordem cronológica para cada assunto pertinente ao projeto, mas isso não é uma regra geral. Ass vezes pode ser importante citar um trabalho mais recente antes de um mais antigo.

O mais simples e recomendável para citar a bibliografia em projetos, relatórios, dissertações ou teses, é usar o número entre chaves, com a mesma fonte das letras do texto, por exemplo: Aaaaa [1]. No caso de publicações deve-se sempre consultar as normas específicas do periódico escolhido. O ponto final ou a vírgula vem sempre depois do número da bibliografia.

Outras alternativas para citação são:

- Sobrescrito entre chaves, por exemplo: Aaaaaa ${ }^{[1]}$. 
- Sobrescrito simples, por exemplo: Aaaaaaa ${ }^{1}$.

Em qualquer caso:

- Se citar mais de uma bibliografia, fora de seqüência, usar vírgulas: por exemplo $[1,3,8]$

- Se citar mais de uma bibliografia, em seqüência, usar traço: [1-5]

- Também é possível citar a bibliografia citando o nome do autor principal e o ano da publicação, e.g., Soares 1989 ou Soares (1989). Neste caso, as publicações do mesmo autor são diferenciadas pelo ano. Se houver autores diferentes com o mesmo sobrenome é necessário incluir as iniciais de ambos antes do sobrenome para diferenciá-los. Cada periódico, livro ou congresso tem a sua norma para citação bibliográfica. Alguns cursos de pós-graduação também têm normas para isso. Existe também uma norma ABNT. Como sabemos, há diversas maneiras de apresentar a bibliografia. Qualquer que seja a norma adotada, ela deverá ser usada para todas as citações em um mesmo texto. Abaixo é fornecida uma sugestão de norma para citação de bibliografia.

- Publicações em periódicos: autor(es), título da publicação, nome do periódico abreviado segundo as normas do Chemical Abstracts (consultar http://www. cas.org), volume em negrito (ano entre parênteses) página inicial e final.

- Livros: autor(es), "nome do livro entre aspas", volume (se houver mais de um), edição (se houver mais de uma), editora, cidade onde foi editado, ano de publicação e página onde se encontra o assunto citado (quando a citação não abrange todo o livro).

- Capítulos de livros: autor(es), título do capítulo, in "nome do livro entre aspas", volume (se houver mais de um), editor seguido de ed., editora, cidade onde foi editado, ano de publicação, página ou número do capítulo.

- Comunicações em congressos: autor(es), título da comunicação, nome do congresso, cidade onde ocorreu o congresso (só citar o país se o nome da cidade não for suficiente para localizá-la), ano, número da comunicação ou página nos Anais ou Proceedings (abrevia-se Proc.).

- Teses e dissertações: Autor, título da Tese, grau (Doutorado, $\mathrm{PhD}$, ou Mestrado, MSc) nome da universidade por extenso, cidade, ano da defesa. Deve-se evitar a citação de Teses se os resultados já tiverem sido publicados. As Teses são mais difíceis de serem encontradas para serem consultadas em comparação às publicações.

- Patentes: autor(es), título, país (nacionalidade), ano, número de registro.
- Pedidos de patente: autor(es), título, país, ano, número de protocolo, data e hora de entrada do pedido.

- Web site: http://www.aaa.bbbbb.xxx , data e hora da consulta.

- Catálogos de produtos: nome comercial do produto seguido do símbolo ${ }^{\circledR}$ ou ${ }^{\mathrm{TM}}$, nome da empresa, local e ano de impressão do catálogo.

Em alguns casos é possível citar uma informação como "comunicação pessoal", mas esta informação será de pouco valor para os leitores do texto. Também há o caso quando uma informação bibliográfica é obtida a partir de uma outra bibliografia. Neste caso usa-se a palavra em latim "apud" para indicar que a citação foi obtida de outra fonte. Fazendo isso, o autor do texto está protegido se a pessoa que citou o segundo trabalho não o fez corretamente. De qualquer forma, só se deve citar trabalhos que foram efetivamente consultados e lidos, senão corre-se o risco de fazer uma citação sem poder comprovar o que foi citado. Aproveito esta seção para lembrar algumas abreviações que podem ser usadas em textos em português ou em inglês: e.g. $=$ exempli gratia $($ por exemplo), i.e. $=$ id est (isto é), ca. = circa (cerca de), et al (e colaborador) e et alia (e colaboradores). Como os romanos dominaram toda a Europa, inclusive a ilha que hoje é o Reino Unido, eles nos legaram muitas palavras latinas que nos podem economizar um longo texto. Portanto temos a liberdade de usar também palavras, prefixos e sufixos de origem latina (ou grega) como: pletora, batocrômico, hipsocrômico, etc.

\section{Patentes}

Para patentes há vários textos com instruções de redação e cada Instituição deve ter um texto apropriado e adequado aos seus interesses. Por exemplo, consultar:

- Escritório de Difusão e Serviços Tecnológicos da Unicamp (http://www.inova.unicamp.br/site/06/)

Em qualquer caso, é bom pesquisar no site

- Instituto Nacional da Propriedade Industrial (INPI) (bttp://www.inpi.gov.br/menu-esquerdo/patente) 
Referências Bibliográficas

1. Eco, U., "Comme si fa una tesi di láurea", Bompiani, Milão, 1977.

2. Schrödinger, E., (http://www.lecb.ncifcrf.gov/ toms/quotes.html), (01/Nov/2001; 14:00h)

3. Rey, L., "Como redigir trabalhos científicos", Editora da USP, São Paulo, 1972.

4. O'Connor, M.; Woodford, F.P., "Writing scientific papers in english”, Elsevier, Amsterdam, 1977.

5. Spector, T., "Writing a scientific manuscript", J. Chem. Educ. 1994, 71:47.

6. Soto-Oviedo, M.A.; Araujo, O.A.; De Paoli, M.A., publicação submetida.

7. Staub, S.; De Paoli, M.-A., relatório técnico, Convênio Unicamp-Receita Federal, 2004. 